\title{
Cognitive failures as predictors of driving errors, lapses, and violations
}

\author{
Wickens, C. M., Toplak, M. E., \& Wiesenthal, D. L. \\ Version Post-Print/Accepted Manuscript \\ Citation Wickens, C. M., Toplak, M. E., \& Wiesenthal, D. L. (2008). Cognitive \\ (published version) failures as predictors of driving errors, lapses, and violations. Accident \\ Analysis and Prevention, 40, 1223-1233.

\section{Copyright / License (c) (7) $\ominus$} \\ This work is licensed under a Creative Commons Attribution- \\ NonCommercial-NoDerivatives 4.0 International License.
}

Publisher's Statement The final publication is available at Elsevier via http://dx.doi.org/10.1016/j.aap.2008.01.006. 
Running head: COGNITIVE FAILURES IN DRIVING

Cognitive Failures as Predictors of Driving Errors, Lapses, and Violations

Christine M. Wickens, Maggie E. Toplak \& David L. Wiesenthal

York University

Please send correspondence to:

David L. Wiesenthal

Department of Psychology

York University

4700 Keele St.,

Toronto, Ontario, M3J 1P3

CANADA

E-mail: davidw@yorku.ca

Phone: 416-736-2100 Ext. 30114

Fax: 416-736-5814 


\begin{abstract}
Dual-process models from the cognitive literature have proposed a taxonomy of cognitive failures in everyday activities, and this novel approach was applied to understanding driver behaviour. This framework was used to examine whether categories of cognitive failure would explain driving errors, driving lapses, and driving violations in a sample of undergraduates at a large urban university. Two types of cognitive failure were examined, one associated with missing affective information and the other associated with a failure to engage effortful processes to override an automatic response. Alexithymia was used as an indicator of missing affective information, and attention regulation, reactivity, and impulsivity were used as indicators of override failure. Relevant demographic variables included gender and hours typically driven. Override failures were significantly associated with driving behaviour in the correlational analyses. In the regression analyses, attention regulation predicted driving errors, and gender, attention regulation, and impulsivity predicted driving violations. The implications of this work include the potential application to driver training, to users of informatic devices (e.g., GPS, cellular phones, messaging systems), and for individuals diagnosed with attention and/or impulsivity problems.
\end{abstract}

Keywords: Driver Behaviour Questionnaire; Cognitive failures; Dual-process models; Individual differences; Attention regulation; Distractibility; Impulsivity 
Cognitive Failures as Predictors of Driving Errors, Lapses, and Violations

\section{Introduction}

The safe operation and manoeuvring of an automobile is an essential skill in our modern society. Driving performance is a particularly important domain of functional behaviour for study, as the consequences of bad driving are enormous, financially and with respect to morbidity (Hennessy and Wiesenthal, 2005a). Therefore, understanding the correlates of good driver behaviour is important for helping drivers function optimally on increasingly congested roads and highways. There has been an increased concern with driver safety which is partly attributable to the potential for distraction caused by the use of cell phones, MP3 players, text messagers, and other electronic devices during driving (Lee, 2007; Strayer and Johnston, 2001; Wiesenthal and Singhal, 2005). These devices are thought to place road users at risk by distraction and increases in cognitive load, but conclusive evidence for this is still needed (Wiesenthal and Singhal, 2005). Part of the difficulty with understanding the relative risk of these devices during driving is that we need a comprehensive model of driver behaviour for understanding how additional driver demands may impact driver behaviour. What is needed is a study that integrates different demographic and psychological individual difference variables using a theoretically-based framework that takes into account the unique contribution of factors related to different driving behaviours. There are models that incorporate the multiple contributors to driving behaviour, including environmental and situational determinants (Matthews, 2001; Shinar, 1998; Taubman-Ben-Ari et al., 2004), but the emphasis here was on demographic and individual difference variables.

There has been a range of variables associated with driver behaviour, including demographic variables such as age, gender, and experience (Lawton et al., 1997b; Wiesenthal 
and Singhal, 2006; Wilson and Daly, 1985), cognitive variables such as distractibility (Strayer and Johnston, 2001) and disregard for negative consequences (Taubman-Ben-Ari et al., 2004), and motivational or affective variables such as driver vengeance and aggression (Hennessy and Wiesenthal, 2004, 2005b; Lonero, 2000; Neighbors et al., 2002). The problem is not a lack of demonstration of important demographic and individual difference variables relevant to understanding driver behaviour. Instead, the difficulty is methodological, in that many of these variables are correlated with each other and with empirically established demographic variables associated with driver behaviour, including age and gender. For example, younger motorists have been found to report more driver aggression than older motorists (Hennessy and Wiesenthal, 2004; Krahé, 2005; Krahé and Fenske, 2002). In addition, associations between these variables may not always go in the expected direction. For example, driving experience may be expected to be associated with better driving performance. Although more years of driving experience have been associated with fewer lapses and errors (Xie and Parker, 2002), higher annual mileage by males has been linked with more aggressive driving behaviour (Lawton et al., 1997a).

In order to address this methodological issue, multiple domains of cognitive and affective control were examined, in conjunction with important demographic variables (i.e., gender and driving experience), to determine whether each of these variables uniquely predict driver behaviour in an undergraduate sample at a large, metropolitan commuter university. A theoretical framework based on dual-process theories of cognitive functioning was proposed in order to provide a structure for categorizing multiple predictors. This framework is a cognitivebased model, as the primary assumption is that errors in driver behaviour are a result of cognitive failures. This model has been applied to other domains involving risk-taking (e.g., the 
conceptualization of the multiple, unique predictors associated with pathological gambling behaviour; Toplak et al., 2007).

\subsection{Dual-process theories of cognition}

The basis of this approach emerges from dual-process models of cognition suggesting that two different types of cognition have different functions, strengths, and weaknesses (Stanovich, 1999, 2004). In this model there are two sets of systems: System 1 (also known as the autonomous set of systems, TASS) is automatic and context-based, whereas System 2 is controlled and requires decontextualization (Stanovich, 1999, 2004; Stanovich and West, 2000). These types of cognition are consistent with the distinction in the cognitive literature between automatic and controlled processes, which has also been used as an important distinction in the driving literature (Brehmer, 1994), but these processes have been theoretically refined and elaborated to encompass a broader set of cognitive activities and domains, including the study of human rationality and decision-making (Stanovich, 1999). System 1 - TASS processes are 'fast and frugal' and activate 'gut' feelings that fit the immediate situation (Gigerenzer and Goldstein, 1996; Reyna and Farley, 2006), much like reflexive behaviours. System 2 analytic processes are slower, more controlled and effortful, and necessitate active consideration of alternatives (Stanovich, 1999, 2004; Stanovich and West, 2000). These systems are likely comprised of many components (Stanovich, 2004). For example, included in System 1 - TASS are processes of implicit and instrumental learning, overlearned associations, and processes of behavioural regulation by the emotions. Included in System 2 are processes related to cognitive abilities, executive processes, and dispositional tendencies related to open-minded thinking.

Both the heuristic (System 1 - TASS) and analytic (System 2) systems can produce response output for the same cognitive problem, and these outputs can often reinforce one 
another. These two sets of processes often work together in tandem. For example, although folk wisdom suggests that emotion and intellect are in a constant struggle, many cognitive science models regard emotions as useful signals for guiding behaviour, such as assisting with the prioritization of goals (Damasio, 1994; Johnson-Laird and Oatley, 1992). This type of behaviour regulation by the emotions is a useful first-pass strategy, however more complicated situations may result in a conflict between the response outputs from these two systems, generating cognitive failure.

\subsection{Cognitive failures}

Based on the dual-process framework, two classes of cognitive failure were examined in the current study.

1.2.1. Missing TASS output.. The first category of cognitive failure is missing TASS output (Stanovich, 2002, in press; Toplak et al., 2007). Although many cognitive science models regard emotions as useful signals for guiding behaviour, such as assisting with the prioritization of goals (Damasio, 1994; Johnson-Laird and Oatley, 1992), there are times when affective information may be lacking. Damasio and colleagues (Bechara et al., 1996; Damasio, 1994), have demonstrated that patients with damage to the ventromedial prefrontal cortex exhibit poor performance on measures of real-life decision-making that are not attributable to deficits related to executive processes, such as working memory (Bechara et al., 1998). Damasio (1994) has termed the somatic marker hypothesis to explain these findings. Somatic markers, or emotions, assist by constraining the decision-making space and giving various alternatives preferential availability over other alternatives (Oatley, 1999). Somatic markers serve an adaptive evolutionary human function, consistent with cognitive science perspectives on the role of emotion (Johnson-Laird and Oatley, 1992). Damasio (1994) argues that his patients with 
ventromedial lesions lack the physiological cues needed to signal risky choices (Bechara et al., 1996, 1997). When important affective information is lacking, this can lead to cognitive failures.

1.2.2. TASS override failure. The second category of cognitive failure has been termed TASS override failure (Stanovich, 2002, in press; Toplak et al., 2007). In complicated situations, the first-pass heuristic strategy that is associated with System 1 - TASS processes may be inadequate, necessitating a more fine-grained response that can only be generated by the more analytic and effortful System 2 processes. TASS override failure occurs when System 1 - TASS processes are insufficient, yet the analytic processes of System 2 are not activated. Failures in attention regulation suggest a lack of engaging analytic processes. In the clinical literature, for example, inattention has been associated with lower performance on measures of executive function (Chhabildas et al., 2001; Martel et al., 2007), which are processes related to the regulation of behaviour generally located in the prefrontal cortex (Pennington and Ozonoff, 1996). Measures related to impulsivity and consideration of future consequences have been used previously as indicators of TASS override failure in pathological gambling (Toplak et al., 2007). Impulsivity involves a lack of accessing inhibitory mechanisms that could deter a behaviour, and consideration of consequences activates possible outcomes that may importantly impact the choice or decision at hand. Too much emotion has been conceptualized as an instance of override failure (Stanovich, 2002).

\subsection{Dual processes and cognitive failures in driving}

This paradigm is useful for understanding the types of cognitive failures that can lead to poor driving performance. Much driving experience is based on overlearned associations and automatic behaviours triggered by situations requiring rapid reaction times and the need to make quick judgments. These behaviours must become automatic in order for one to become a 
proficient driver (e.g., being prepared to brake when the car ahead suddenly slows down, making a lane change, or turning on the windshield wipers when it begins to rain). Affective reactions, such as fear, may be useful if they reduce the driver's reaction time in situations where the driver must brake suddenly - this would be a situation where the two systems are working in synchronization. However, a lack of affective information in such a case could be hazardous if it prevents the driver from reacting in time; this would be an example of a cognitive failure involving missing TASS output. Drivers also encounter situations where there is too much affective information that they must actively override or inhibit; for example, in cases of driver rage and driver vengeance. The regulation of attention and consideration of options and outcomes of actions are also important during driving. For example, analytic processes may need to be engaged in order to realize that one needs to slow down after coming off the highway into a reduced speed zone. Likewise, deciding whether to take a detour from a congested highway may necessitate analytic processes to override the heuristic tendency to stay on the highway. These latter two examples reflect override failures.

There is substantial literature to suggest that override failure is related to driver mistakes. The case of driver vengeance and aggression (Hennessy and Wiesenthal, 2004; Krahé, 2005; Krahé and Fenske, 2002) demonstrates the failure to override affective TASS input. Consideration of consequences, engaging attentional resources, and impulsivity have also been associated with negative driving outcomes. For instance, disregard for negative consequences has been associated with reckless driving (Taubman-Ben-Ari et al., 2004). Failures to engage, maintain, and regulate attention have been related to lane deviation, inconsistent speed, and unsafe following distance (de Waard and Brookhuis, 1997). DePasquale et al. (2001) presented participants with aversive driving events and asked participants to select their most likely 
response to the event from a list of responses that varied in degree of emotional reaction and retaliation. DePasquale and colleagues reported that impulsivity was correlated with selfreported aggressive responding. Barkley and colleagues demonstrated that drivers who had been diagnosed with attention-deficit/hyperactivity disorder (ADHD), a common symptom of which is impulsive tendencies, received more traffic citations for speeding, licence suspensions, and vehicular collisions (Barkley et al., 2002; Jerome et al., 2006; Murphy and Barkley, 1996). Missing TASS output has not been implicated in driver behaviour, but was explored here as another type of cognitive failure that may be associated with driver behaviour.

\subsection{Purpose of the current study}

The purpose of this study was to apply this novel framework to understand how different types of cognitive failure relate to driver behaviour. One measure of missing TASS output was included, namely, the ability of individuals to identify and label their affective reactions. The category of TASS override failure included measures related to the regulation of attention, impulsivity, consideration of future consequences, and the degree to which individuals differ in their subjective experience of stimulation or reactivity. Three types of driver behaviour were assessed: errors, lapses, and violations. Errors included instances of failure to successfully carry out an intended action leading to potentially dangerous manoeuvres. Lapses included behaviours related to attention or memory failures which can sometimes impact driver safety. Violations included deliberate defiance of safe driving practices. In summary, the dual-process model provides a novel integration of variables associated with driver behaviour. This study examined the extent to which these variables are differentially associated with various driving outcomes.

\subsection{Hypotheses}

The following hypotheses were proposed: 
1. Variables related to two types of cognitive failure (missing TASS output and TASS override failure) would be associated with driving behaviour. For the measures of missing TASS output, it was hypothesized that difficulties with identifying affect would be associated with suboptimal driving behaviours. For the measures of override failure, it was hypothesized that failures in regulating attention, failures in inhibiting impulsive tendencies, a lack of consideration of outcomes, and reactivity would be associated with less optimal driving behaviour. It was also expected that the demographic variables of gender and driving experience would predict driving behaviour.

2. A differential pattern of associations between the measures of cognitive failure and the different driving behaviours was hypothesized. Specifically, failures in attention and reactivity should be associated with driving errors and lapses, whereas impulsivity should be associated with driver violations. Each of these variables was expected to predict unique variance associated with the different driving behaviours.

\section{Method}

\subsection{Participants}

In exchange for psychology course credit, Canadian undergraduate students in a major university served as participants in this study. A total of 115 participants (58 males and 57 females) took part in the study. Their mean age was 20.82 years $(S D=5.14)$. To be eligible for participation in the study, participants were required to hold a valid driver's licence or learner's permit. Participants reported that they spent $1.79 \mathrm{~h}(1 \mathrm{~h}$ and $47 \mathrm{~min})$ per day driving, however there was extreme variation in scores. Responses ranged from 0.17 to $5.00 \mathrm{~h}$ (10 min to $5 \mathrm{~h}$ ), generating a standard deviation of 1.21 ( $1 \mathrm{~h}$ and $13 \mathrm{~min})$.

\subsection{Materials}




\subsubsection{Driving behaviour}

2.2.1.1. Driver Behaviour Questionnaire (DBQ). The DBQ (Lawton et al., 1997a; Parker et al., 1995; Reason et al., 1990) measured three types of driving behaviours: errors (i.e., failure to successfully carry out an intended action leading to potentially dangerous manoeuvres), lapses (i.e., attention or memory failures which sometimes impact driver safety), and violations (i.e., deliberate defiance of safe driving practices). The current study used a version of the DBQ adapted for North American drivers (see Reimer et al., 2005). The measure included 24 items rated on a 6 -point scale ranging from ' $0=$ never' to ' $5=$ nearly all the time'. There were three dependent variables, including reported errors, lapses, and violations during driving.

\subsubsection{Missing TASS output}

2.2.2.1. Alexithymia Scale-Revised. This 20-item scale, revised by Bagby et al. (1994), assessed a lack of emotional awareness. The measure has three subscales: Difficulty Identifying Feelings (e.g., "When I am upset, I don't know if I am sad, frightened or angry”), Difficulty Describing Feelings (e.g., "It is difficult for me to find the right words for my feelings"), and Externally Oriented Thinking (e.g., "I prefer talking to people about their daily activities rather than their feelings"). Items were rated on a 6-point scale ranging from ' $1=$ strongly disagree' to ‘ 6 = strongly agree'. One composite scale was created to assess a general lack of emotional awareness, which served as the dependent measure.

\subsubsection{TASS override failure}

2.2.3.1. Differential Attention Processes Inventory (DAPI). The DAPI assessed individual differences in focused and dual attention (Crawford, 1993; Crawford et al., 1993; Grumbles and Crawford, 1981). It contained 40 items related to everyday experiences involving attention, ignoring distractions, and performing physical and cognitive tasks simultaneously. Participants 
rated their level of agreement with each statement on a 7 -point scale ranging from ' 1 = never' to '7 = always'. The scale consisted of four subscales: Moderately Focused Attention (e.g., "Can you concentrate on reading or studying while in a noisy room?"), Extremely Focused Attention (e.g., "Can you lose yourself in thought so that you are hardly aware of the passage of time?"), Dual Attention Cognitive-Cognitive (e.g., "Can you read or study easily while at the same time listen easily to a conversation?"), and Dual Attention Cognitive-Physical (e.g., "Can you talk on the telephone while doing some other physical activity?"). Scores on each of the four subscales constituted the dependent measures.

2.2.3.2. Adult Self-Report Scale (ASRS). The ASRS was developed by a World Health Organization (WHO) workgroup to assess difficulties associated with ADHD in adults (Kessler et al., 2005). Nine questions related to inattention were included (e.g., "When you have a task that requires a lot of thought, how often do you avoid or delay getting started?"). Participants rated the frequency with which they experienced these difficulties on a 5-point rating scale, labeled Never, Rarely, Sometimes, Often, and Very Often. A composite scale for Inattention served as the dependent measure.

\subsubsection{Impulsivity Scale. A modified subscale of the $\mathrm{I}_{7}$ Impulsivity Questionnaire} (Eysenck et al., 1985) was included. The original subscale utilized a question format (e.g., "Do you often buy things on impulse?"), whereas the current study utilized a statement format (e.g., "I often buy things on impulse"). The subscale consisted of 19 items that were rated on a 6-point scale ranging from ' $0=$ never' to ' $5=$ always'.

\subsubsection{Consideration of Future Consequences Scale (CFC). The CFC measured the} extent to which individuals consider distant outcomes when choosing their present behaviour (Strathman et al., 1994). The measure consisted of 12 items (e.g., "I only act to satisfy immediate 
concerns, figuring the future will take care of itself' [reverse scored]) rated on a 6-point scale ranging from ' $1=$ strongly disagree' to ' $6=$ strongly agree'.

2.2.3.5. Reactivity Scale. This scale (Kohn, 1985), derived from stimulus-intensitymodulation theory (see Barnes, 1976; Eysenck, 1967; Pavlov, 1960; Petrie, 1967; Strelau, 1983), assesses how individuals differ in their subjective experience of stimulation, such as pain and noise. Some individuals subjectively amplify stimulus intensity, whereas others attenuate it. The Reactivity Scale contains 24 items (e.g., "If I went on an ocean voyage, I'd be sure to get seasick", "I can't stand staying in a sauna or steam bath for very long") that are rated on a 5point scale ranging from ' $1=$ disagree strongly' to ' $5=$ agree strongly'.

\subsubsection{Impression Management}

As the measures were self-report measures, an impression management scale was included as a control variable for social desirability. A 5-item scale from Paulhus (1991) was employed, and included items such as: "I sometimes tell lies if I have to." The same rating scale was used as for the CFC scale.

\section{Results}

\subsection{Reliability of the measures}

Reliability coefficients were computed for each of the measures used in the current study, which are displayed in Table 1. Most measures demonstrated moderate to strong reliability $(\alpha=$ .75 to $\alpha=.96$; see Nunnally and Bernstein (1994) for a discussion of standards of reliability). In

the case of driving errors, the elimination of one item in the scale (i.e., try to pass another car that is signaling a left turn) significantly increased the scale's reliability coefficient. Therefore, the revised 7-item scale was used in the statistical analyses. Student participants reported significant difficulty in estimating daily, weekly, or annual mileage; therefore, average number of hours of 
daily driving was used as a substitute for mileage as a demographic predictor variable. It should be noted that for all parametric tests, the mean number of hours of daily driving was logtransformed in order to make the distribution of scores more normal. A constant of .834 was added to all reported values before the log transformation so that the minimum value of this variable equaled one (Osborne, 2002).

\subsection{Gender differences}

Table 2 displays mean scores for males and females on all of the measures, including average number of hours spent driving each day. Several significant gender differences emerged, but given the large number of tests conducted, a Bonferroni adjustment requiring a $p$-value of $.004(\alpha / 13)$ was considered when reviewing these results. Using these criteria, males reported significantly more driving violations than females and significantly lower levels of reactivity than females.

\subsection{Correlational analyses}

Correlational analyses were performed among the variables associated with cognitive failure, which are displayed in Table 3. Several of these measures were intercorrelated, including associations among the missing TASS output measure and the override failure measures, but these associations were typically in the expected direction (for example, higher alexithymia was associated with more inattention). Correlations among the different driving outcome measures were also examined. Significant intercorrelations between errors and lapses $(r=.60, p<.001)$, errors and violations $(r=.37, p<.001)$, and lapses and violations $(r=.25, p<.01)$ were obtained. Notably, the strongest intercorrelation was between driving errors and lapses.

Correlational analyses were performed between driving errors, lapses, and violations and the measures of cognitive failure, which are displayed in Table 4. Many of the TASS override 
variables were significantly correlated with driving behaviour, but not the missing TASS output variable. Specifically, four of the TASS override failure variables were significantly correlated with driving errors: the DAPI - Extremely Focused Attention and the Inattention scales were the most highly correlated with driving errors $(r=.36, p<.001$ and $r=.31, p<.001$, respectively), and the Impulsivity Scale was less strongly, but still significantly correlated with driving errors $(r=.27, p<.01)$. The same three TASS override variables were significantly correlated with driving lapses, with all three demonstrating fairly equivalent associations $(r=.38, p<.001 ; r=$ $.36, p<.001 ; r=.34, p<.001$, respectively). For driving violations, the Reactivity Scale $(r=-$ $.29, p<.01)$, DAPI - Extremely Focused Attention $(r=.25, p<.01)$, DAPI - Dual Attention with two Cognitive Tasks $(r=.20, p<.05)$, Impulsivity Scale $(r=.47, p<.001)$, and CFC scale $(r=-.30, p<.001)$ were all significantly correlated, with the strongest correlation obtained with the Impulsivity Scale.

The alexithymia scale was not significantly correlated with driving errors, lapses, and violations. The DAPI - Moderately Focused Attention and DAPI - Dual Attention (with Physical and Cognitive Tasks) also failed to correlate with these DBQ subscales. There was also no association between impression management and the DBQ subscales. Given the lack of significant correlation with driving errors, lapses, or violations, these latter variables were not included in the following regression analyses.

\subsection{Regression analysis}

The current strategy was to use a regression analysis with a hierarchical entry procedure. Gender and mean number of hours spent driving per day were entered in the first block and the other predictor variables were entered in the second block. Unfortunately, thirteen participants failed to report their average daily driving times, resulting in a slightly reduced $N$ for the 
regression analyses. Given the multiple correlations obtained in Table 4, the goal was to determine which TASS override failure variables that had been significantly correlated with the DBQ subscales would survive when entered simultaneously in the second block. A separate regression analysis was performed for each of the driving behaviour outcome measures, including errors, lapses, and violations. The results of these regression analyses are presented in Table 5.

\subsubsection{Driving errors}

Of the three predictor variables tested, based on the correlation matrix in Table 4, only the DAPI - Extremely Focused Attention made a significant positive contribution to driving errors, explaining nearly $4 \%$ of the unique variance associated with driving errors. The final model accounted for approximately $14 \%$ of the variance in driving errors.

\subsubsection{Driving lapses}

Although none of the examined predictors entered as significant unique predictors of driving lapses, the DAPI - Extremely Focused Attention $(p=.056)$ and the Impulsivity Scale $(p$ $=.079)$ came very close to significance. Collectively, the predictors in the final model accounted for approximately $19 \%$ of the variance in driving lapses.

\subsubsection{Driving violations}

In this model, gender entered as a significant predictor of driving violations. Based on the means listed in Table 2, it is clear that males reported significantly more driving violations than did females. In addition, the mean number of hours spent driving per day approached significance $(p=.058)$, suggesting that individuals who spend more time on the roadways are more likely to commit driving violations. These two variables explained nearly $9 \%$ and $5 \%$ unique variance, respectively, of the total variance associated with driving violations. The two 
TASS override failure variables (i.e., the DAPI - Extremely Focused Attention and the Impulsivity Scale) entered as significant predictors, explaining 3\% and 6\% of the unique variance, respectively. The Reactivity Scale, also measuring TASS override failure, also approached significance. Collectively, the predictors in the final model accounted for approximately $34 \%$ of the variance in driving violations.

\section{Discussion}

The current study utilized a dual-process framework to examine whether two categories of cognitive failure, specifically missing TASS output and TASS override failure, would significantly predict driving behaviour. The results of the current study suggest that measures of TASS override failure were associated with driving behaviour. In particular, the various measures of TASS override failure were differentially associated with driving errors, lapses, and violations. In terms of driving errors, the DAPI - Extremely Focused Attention was a significant predictor. For driving lapses, the same variable approached statistical significance, as did selfreported impulsive tendencies. Driving violations were significantly predicted by gender, DAPI - Extremely Focused Attention, and impulsivity, while mean hours driving per day and reactivity approached significance.

The results indicate that demographic variables (gender and mean hours driving per day) and variables indicating TASS override failure were significantly associated with driving behaviour. In addition, there were important differences in which of these variables predicted different driving behaviour outcomes (i.e., errors, lapses, and violations). The DAPI - Extremely Focused Attention subscale was associated with both errors and lapses. Items composing this subscale included questions about getting lost in thought, forgetting that someone else is in the room with you, and arriving late for appointments because of getting so involved in something. 
Indeed, this scale was highly correlated with the Inattention Scale (see Table 3), further validating that the DAPI - Extremely Focused Attention is related to a failure to engage the attention required for a given task. It is likely that the DAPI - Extremely Focused Attention measure accounted for common variance shared by the Inattention Scale, making the latter measure redundant in the regression analysis. Only the DAPI - Extremely Focused Attention scale, an attention regulation variable, significantly predicted driving errors, such as failing to notice pedestrians when turning onto a side street and failing to "Stop" or "Yield" at a sign. Based on dual-process models, this type of cognitive failure may be conceptualized as a lack of engagement of analytic processes. Others have described this type of failed attention regulation as mind wandering, where executive control may shift away from a primary task to processing an alternative goal (Smallwood and Schooler, 2006). The failure to properly regulate attention, as measured in the current study, may be akin to the type of inattention experienced by those diagnosed with ADHD (APA, DSM-IV-TR, 2000), based on the significant correlation between the DAPI - Extremely Focused Attention and Inattention items for the ASRS questionnaire. Attention regulation marginally predicted driving lapses and significantly predicted driving violations. The attention regulation individual difference variables studied here suggest that there may be considerable variation in how drivers perform in dual task situations (e.g., conducting conversations over cellular telephones, talking to passengers when attempting to locate a street address). While not all conversations present the same workload demands, it should be recognized that individuals may also vary in their ability to deal with distractions while operating a vehicle in traffic (Wiesenthal and Singhal, 2005).

Gender, attention regulation, and impulsivity emerged as significant predictors of driving violations. Reactivity entails a higher sensitivity to stimulation. It was predicted that greater 
reactivity would interfere with the engagement of analytic processes resulting in more driving errors and lapses. Instead, reactivity was negatively related to driving violations, suggesting that reactivity may make drivers hypersensitive and thus less likely to commit violations such as becoming impatient with a slow driver in the passing lane and passing on the right, or vengefully chasing another driver. That gender was implicated in driving violations is consistent with the finding that men are generally more likely to be involved in traffic violence than women (Hennessy et al., 2004). Hennessy and Wiesenthal (2005b) found that driver violence was predicted by the interaction of violations, gender, and vengeful attitudes.

It is also important to give some consideration to why different variables were associated with driving errors, lapses, and violations. When intercorrelations between the different driving behaviour measures were examined, it was found that errors, lapses, and violations were significantly intercorrelated with one another. The strongest correlation between errors and lapses is consistent with the regression analyses, indicating that attention regulation likely contributes to performance in these two domains. Violations were less strongly associated with errors and lapses, which is also consistent with the regression analyses, as gender and reactivity were also implicated in these analyses. The category of violations seems to be a qualitatively different category of behaviours than errors and lapses. These results suggest that different types of TASS override failure may explain these different problematic driving behaviours. That attention regulation was implicated with driving errors and lapses suggests that these types of driver mistakes may be better explained by a failure to engage analytic processes. The role of impulsivity in driving lapses and violations suggests that the analytic system was unable to override the impulsive tendencies on these driving behaviours, and indeed more unique variance was accounted for by impulsivity in these regression analyses than by gender and attention 
regulation. Alternatively, alexithymia, the measure used as an indicator of missing TASS output, was not found to be related to driving behaviour. Together, this study provides a framework for examining how different types of TASS override failure may underlie different types of driver mistakes. Cognitive failures related to TASS override failure, including attention regulation and impulsivity, predicted driver mistakes; whereas the measure of missing TASS output did not.

This study represents an important first step in understanding the multiple variables that have relative contributions to predicting driver behaviour. These results also have important practical and clinical applications. That different types of TASS override failure were implicated for different facets of driver behaviour suggests that those involved in driver instruction consider teaching different skill sets for different driver behaviours. For example, instructors should be teaching explicit strategies for maintaining focus and attention during driving, as well as strategies for inhibiting impulsive and properly calibrating reactive tendencies. This study also highlights how multiple domains of driver behaviour should be separately targeted in intervention efforts. Future studies should consider further ways to examine the types of variables that have been used here. For example, examination of other types of cognitive failure or TASS override failures would be a productive direction, such as examining other measures of affect, including the contribution of driver rage and vengeance. In addition, as the current study used many self-report measures that are somewhat intercorrelated, it would be useful to map the current findings on to behavioural observations in order to refine the variables examined.

One growing concern of both the public and governments has been the issue of distraction resulting from the use of various telematic devices in vehicles (National Highway Traffic Safety Adminstration (NHTSA), 2004; Road Safety and Motor Vehicle Regulation Directorate, 2005). This concern regarding driver distraction is supported by the results of the 
current study, namely, the significant role of attention regulation in driver errors and violations. Telematic devices are cellular telephones, navigational devices, adaptive speed control, radar detectors, and Internet access (Road Safety and Motor Vehicle Regulation Directorate, 2005), although other devices such as video disc players, e-mail readers, lane change aides, and parking assistance tools may also be considered. Distraction may not necessarily be limited to the use of these high technology developments - a driver talking to passengers resulted in slower reactions and greater errors on attentional and detection tasks (Amado and Ulupinar, 2005). While telematic devices may serve as potential distractions for the driver, the present results indicate that the level of distraction may vary considerably for individuals possessing varying levels of cognitive abilities. When engaged in dual task information processing situations, such as invehicle operation of telematic devices, the ability to maintain control over analytic processes has been demonstrated to differ between those possessing bilingual fluency, unilingual fluency, and levels between those two linguistic skill levels (Telner et al., 2007). The measures used in the present study suggest that these instruments could be applied to specific groups of individuals (e.g., young drivers, older drivers) who have demonstrated their higher rates of collision (see Barkley and Cox, 2007; Jerome et al., 2006) in order to gauge how their cognitive performance correlates with their driving history. These instruments could also be used to measure the relative distraction that each new telematic device may cause. Once this level of distraction is ascertained, motor vehicle agencies will be able to develop policy decisions based upon evidence-based practice.

The current results also have important implications for the study of clinical conditions, such as drivers diagnosed with ADHD. Attention regulation and impulsivity are two of the key symptom sets associated with ADHD (APA, DSM-IV-TR, 2000), and these entered as 
significant predictors of driver behaviour. It has been reported that adults with ADHD display significantly more driving errors, lapses, and violations on the DBQ than controls (Reimer et al., 2005). Other studies have demonstrated that adults with ADHD displayed lower scores on a test of driving rules (Barkley et al., 2002), were more likely to be at fault for crashes (Barkley et al., 1993), displayed more erratic steering during a computer-simulated driving test (Barkley et al., 1996), committed more speeding violations (Murphy and Barkley, 1996), and demonstrated more driving anger and expression of aggression (Richards et al., 2002, 2006) relative to nonclinical controls. Importantly, while stimulant medication has been shown to improve driver performance in driving simulator research (Cox et al., 2000), the impairments reported that are related to traffic violations and frustration management may necessitate consideration of other treatment approaches.

Overall, this study represents an important first step for providing a theoretical and methodological approach to study the multiple affective and cognitive processes involved, sometimes simultaneously, during the successful operation of a motor vehicle. The utility of this theoretical approach and method provides a conceptual working model for understanding individual difference variables related to driver behaviour, but more of such work and more refined methods will be needed, including direct measurement of the constructs examined in this study. Such a model is needed in order to better understand how additional driver demands interact with individual difference variables, how to inform policy on the utility and dangers of new devices available for drivers, and how to target intervention and driver training for different types of driver mistakes. 


\section{Acknowledgements}

The authors wish to acknowledge support from a York University Faculty of Arts Research Grant (MET and DLW), as well as research grants from the Social Sciences and Humanities Research Council (MET) and AUTO21 (DLW). Christine M.Wickens held a Social Science and Humanities Research Council Doctoral Fellowship.

The authors extend their thanks to Helen Crawford for providing the Differential Attention Processes Inventory and Rainier Casido, Amanda Near, and Shannon Roszell for their assistance in collecting and entering data for this study. 


\section{References}

Amado, S. \& Ulupinar, P. (2005). The effects of conversation on attention and peripheral detection: Is talking with a passenger and talking on the cell phone different? Transportation Research Part F, 8, 383-395.

American Psychiatric Association. (2000). Diagnostic and statistical manual of mental disorders, $4^{\text {th }}$ edition, Text Revision (DSM-IV-TR). Washington, DC: American Psychiatric Association.

Bagby, R. M., Parker, J. D. A., \& Taylor, G. J. (1994). The twenty-item Toronto Alexithymia scale-I. Item selection and cross-validation of the factor structure. Journal of Psychometric Research, 38, 23-31.

Barkley, R. A. \& Cox, D. (2007). A review of driving risks and impairments associated with attention-deficit/hyperactivity disorder and the effects of stimulant medication on driving performance. Journal of Safety Research, 38, 113-128.

Barkley, R. A., Guevremont, D. C., Anastopoulos, A. D., DuPaul, G. J., \& Shelton, T. L. (1993). Driving-related risks and outcomes of attention deficit hyperactivity disorder in adolescents and young adults: A 3- to 5- year follow-up survey. Pediatrics, 92, 212-218.

Barkley, R. A., Murphy, K. R., DuPaul, G. J., \& Bush, T. (2002). Driving in young adults with Attention Deficit Hyperactivity Disorder: Knowledge, performance, adverse outcomes, and the role of executive functioning. Journal of the International Neuropsychological Society, 8, 655-672.

Barkley, R. A., Murphy, K. R., \& Kwasnik, D. (1996). Motor vehicle driving competencies and risks in tends and young adults with attention deficit hyperactivity disorder. Pediatrics, 98, 1089-1095. 
Barnes, G. E. (1976). Individual differences in perceptual reactance: A review of the stimulusintensity modulation individual-difference dimension. Canadian Psychological Review, $17,29-52$.

Bechara, A., Damasio, H., Tranel, D., \& Anderson, S. W. (1998). Dissociation of working memory from decision-making within the human prefrontal cortex. Journal of Neuroscience, 18, 428-437.

Bechara, A., Damasio, H., Tranel, D., \& Damasio, A. R. (1997). Deciding advantageously before knowing the advantageous strategy. Science, 272, 1293-1295.

Bechara, A., Tranel, D., Damasio, H., \& Damasio, A. R. (1996). Failure to respond automatically to anticipated future outcomes following damage to prefrontal cortex. Cerebral Cortex, 6, 215-225.

Brehmer, B. (1994). Psychological aspects of traffic safety. European Journal of Operational Research, 75, 540-552.

Chhabildas, N., Pennington, B. F., \& Willcutt, E. G. (2001). A comparison of the neuropsychological profiles of the DSM-IV subtypes of ADHD. Journal of Abnormal Child Psychology, 29, 529-540.

Cox, D. J., Merkel, R. L., Kovatchev, B., \& Seward, R. (2000). Effect of stimulant medication on driving performance of young adults with attention-deficit hyperactivity disorder: A preliminary double-blind placebo controlled trial. Journal of Nervous and Mental Disorders, 189, 63-64.

Crawford, H. J. (1993). Differential Attentional Processes Inventory: Sustained and dual attentional styles inventory that discriminates between hypnotic susceptibility level. Unpublished manuscript. 
Crawford, H. J., Brown, A., \& Moon, C. (1993). Sustained attentional and diattentional abilities: Differences between low and highly hypnotizable persons. Journal of Abnormal Psychology, 102, 534-543.

Damasio, A. R. (1994). Descartes' error: Emotion, reason, and the human brain. New York: Avon Books.

de Waard, D., \& Brookhuis, K. A. (1997). On the measurement of driver mental workload. In T. Rothengatter \& E. C. Vaya (Eds)., Traffic \& transport psychology: Theory and application (pp.161-171). Amsterdam: Pergamon.

DePasquale, J. P., Geller, E. S., Clarke, S. W., \& Littleton, L. C. (2001). Measuring road rage: Development of the Propensity for Angry Driving Scale. Journal of Safety Research, 32, $1-16$.

Eysenck, H. J. (1967). The biological basis of personality. Springfield, IL.: C. C. Thomas. Eysenck, S., Pearson P. R., Easting, G., \& Allsopp, J. F. (1985). Age norms for impulsiveness, venturesomeness and empathy in adults. Personality and Individual Differences, 5, 613619.

Gigerenzer, G., \& Goldstein, D. G. (1996). Reasoning the fast and frugal way: Models of bounded rationality. Psychological Review, 103, 650-669.

Grumbles, D., \& Crawford, H. J. (1981). Differential attentional skills and hypnotizability. Paper presented at the annual meeting of the Society for Clinical and Experimental Hypnosis, Portland, OR.

Hennessy, D. A. \& Wiesenthal, D. L. (2004). Age and vengeance as predictors of mild driver aggression. Violence and Victims, 19, 469-477. 
Hennessy, D. A., \& Wiesenthal, D. L. (Eds.). (2005a). Contemporary issues in road user behavior and traffic safety. New York: Nova Science Publishers.

Hennessy, D. A. \& Wiesenthal, D. L. (2005b). Driving vengeance and willful violations: Clustering of problem driving attitudes. Journal of Applied Social Psychology, 35, 61-79.

Hennessy, D. A., Wiesenthal, D. L., Wickens, C., \& Lustman, M. (2004). The impact of gender and stress on traffic aggressions: Are we really that different? In J. P. Morgan (Ed.), Focus on aggression research. New York: Nova Science Publishers.

Jerome, L., Habinski, L., \& Segal, A. (2006). Attention-deficit/hyperactivity disorder (ADHD) and driving risk: A review of the literature and a methodological critique. Current Psychiatry Reports, 8, 416-426.

Johnson-Laird, P., \& Oatley, K. (1992). Basic emotions, rationality, and folk theory. Cognition and Emotion, 6, 201-223.

Kessler, R. C., Adler, L., Ames, M., Demler, O., Faraone, S., Hiripi, E., Howes, M. J., Jin, R., Secnik, K., Spencer, T., Ustun, T. B., \& Walters, E. E. (2005). The World Health Organization Adult ADHD Self-Report Scale (ASRS). Psychological Medicine, 35, 245256.

Kohn, P. M. (1985). Sensation seeking, augmenting-reducing, and strength of the nervous system. In J. T. Spence \& C. E. Izard (Eds.), XXIII International Congress of Psychology: Vol. 5. Motivation, emotion, and personality (pp. 167-173). New York: Elsevier Science Publishing Company, Inc.

Krahé, B. (2005). Predictors of women's aggressive driving behavior. Aggressive Behavior, 31, 537-546. 
Krahé, B., \& Fenske, I. (2002). Predicting aggressive driving behavior: The role of macho personality, age, and power of car. Aggressive Behavior, 28, 21-29.

Lawton, R. J., Parker, D., Manstead, A. S. R., \& Stradling, S. G. (1997). The role of affect in predicting social behaviours: the case of road traffic violations. Journal of Applied Social Psychology, 27, 1258-1276.

Lawton, R. J., Parker, D., Stradling, S. G., \& Manstead, A. S. R. (1997). Self-reported attitude towards speeding and its possible consequences in five different road contexts. Journal of Community and Applied Social Psychology, 7, 153-165.

Lee, J. D. (2007). Technology and teen drivers. Journal of Safety Research, 38, 203-213. Special Issue: Novice teen driving: GDL and beyond - Research foundations for policy and practice symposium.

Lonero, L. P. (2000). A preliminary heuristic model of aggressive behaviour in drivers. Paper presented at the Aggressive Driving Issues On-line Conference. Retrieved June 26, 2001 from http://www.aggressive.drivers.com/board/messages/25/41.html

Martel, M., Nikolas, M., \& Nigg. J. T. (2007). Executive function in adolescents with ADHD. Journal of the American Academy of Child and Adolescent Psychiatry, 46, 1437-1444.

Matthews, G. (2001). A transactional model of driver stress. In P. A. Hancock \& P. A. Desmond (Eds.), Stress, workload, and fatigue (pp. 133-163). Mahwah, New Jersey: Lawrence Erlbaum.

Murphy, K., \& Barkley, R. A. (1996). Attention Deficit Hyperactivity Disorder in adults: Comorbidities and adaptive impairments. Comprehensive Psychiatry, 37, 393-401. National Highway Traffic Safety Administration. (2004). National survey of distracted and drowsy driving attitudes and behaviors: 2002. Washington, DC: National Highway 
Traffic Safety Administration. Retrieved July 21, 2004 from http://www.nhtsa.dot.gov/people/injury/drowsy_driving1/survey-distractive03/

Neighbors, C., Vietor, N. A., \& Knee, C. R. (2002). A motivational model of driving anger and aggression. Personality and Social Psychology Bulletin, 28, 324-335.

Nunnally, J. C., \& Bernstein, I. H. (1994). Psychometric theory ( ${ }^{\text {rd }}$ ed.). Toronto: McGraw-Hill, Inc.

Oatley, K. (1999). Emotions. In R. A. Wilson \& F. C. Keil (Eds.), The MIT encyclopedia of the cognitive sciences. Cambridge, MA: The MIT Press.

Osborne, J. (2002). Notes on the use of data transformations. Practical Assessment, Research \& Evaluation, 8(6). Retrieved November 15, 2007 from http://PAREonline.net/getvn.asp?v=8\&n=6 .

Parker, D., West, R., Stradling, S., \& Manstead, A. S. R. (1995). Behavioral characteristics and involvement in different types of traffic accident. Accident Analysis and Prevention, 27 (4), 571-581.

Paulhus, D. L. (1991). Measurement and control of response bias. In J. P. Robinson, P. Shaver, \& L. S. Wrightsman (Eds.), Measures of personality and social psychological attitudes (pp. 17-59). San Diego, CA: Academic Press.

Pavlov, I. P. (1960). Conditioned reflexes, an investigation of the physiological activity of the cerebral cortex (G. V. Anrep, Trans.). New York: Dover Publications. (Originially published in 1927).

Pennington, B. F., \& Ozonoff, S. (1996). Executive functions and developmental psychopathology. Journal of Child Psychology and Psychiatry, 37, 51-87.

Petrie, A. A. (1967). Individuality in pain and suffering. Chicago: University of Chicago Press. 
Reason, J. T., Manstead, A., Stradling, S., Baxter, J., \& Campbell, K. (1990). Errors and violations on the roads: A real distinction? Ergonomics, 33 (10/11), 1315-1332.

Reimer, B., D’Ambrosio, L. A., Gilbert, J., Coughlin, J. F., Biederman, J., Surman, C., Fried, R. \& Aleardi, M. (2005). Behavior differences in drivers with attention deficit hyperactivity disorder: The driving behavior questionnaire. Accident Analysis and Prevention, 37, 9961004.

Reyna, V. F., \& Farley, F. (2006). Risk and rationality in adolescent decision making. Psychological Science in the Public Interest, 7, 1-44.

Richards, T., Deffenbacher, J., \& Rosen, L. (2002). Driving anger and other driving-related behaviors in high and low ADHD symptom college students. Journal of Attention Disorders, 6, 25-38.

Richards, T., Deffenbacher, J., Rosen, L., Barkley, R. A., \& Rodricks, T. (2006). Driving anger and driving behaviour in adults with ADHD. Journal of Attention Disorders, 10, 54-64.

Road Safety and Motor Vehicle Regulation Directorate (2005). Strategies for reducing driver distraction from in-vehicle telematics devices: Report on industry and public consultations. Ottawa, ON: Transport Canada.

Shinar, D. (1998). Aggressive driving: The contribution of the drivers and the situation. Transportation Research, Part F 1, 137-160.

Smallwood, J., \& Schooler, J. W. (2006). The restless mind. Psychological Bulletin, 132, 946958.

Stanovich, K. E. (1999). Who is rational? Studies of individual differences in reasoning. Mahweh, NJ: Erlbaum. 
Stanovich, K. E. (2002). Rationality, intelligence, and levels of analysis in cognitive science: Is dysrationalia possible? In R. J. Sternberg (Ed.), Why smart people can be so stupid. New Haven, CT: Yale University Press.

Stanovich, K. E. (2004). The robot's rebellion: Finding meaning in the age of Darwin. Chicago: University of Chicago Press.

Stanovich, K. E. (in press). Notes on the reflective, algorithmic, and autonomous mind: From dual-process to tri-process models. To appear in the conference volume from: In two minds: Dual-process theories of reasoning and rationality. Fitzwilliam College, Cambridge University.

Stanovich, K. E., \& West, R. F. (2000). Individual differences in reasoning: Implications for the rationality debate? Behavioral and Brain Sciences, 23, 645-726.

Strathman, A., Gleicher, F., Boninger, D. S., \& Edwards, C. S. (1994). The consideration of future consequences: Weighing immediate and distant outcomes of behavior. Journal of Personality and Social Psychology, 66, 742-752.

Strayer, D. L., \& Johnston, W. A. (2001). Driven to distraction: Dual-task studies of simulated driving and conversing on a cellular telephone. Psychological Science, 12, 462-466.

Strelau, J. (1983). Temperament, personality, activity. London: Academic Press.

Taubman-Ben-Ari, O., Mikulincer, M., \& Iram, A. (2004). A multi-factorial framework for understanding reckless driving - appraisal indicators and perceived environmental determinants. Transportation Research Part F, 7, 333-349.

Telner, J., Wiesenthal, D. L., Bialystok, E., \& York, M. (2007). The effects of second language cellular telephone conversations on simulated driving. Paper presented at the $38^{\text {th }}$ Annual Conference of the Association of Canadian Ergonomists, Toronto, Ontario, Canada. 
Toplak, M. E., Liu, E., Macpherson, R., Toneatto, T., \& Stanovich, K. E. (2007). The reasoning skills and thinking dispositions of problem gamblers: A dual-process taxonomy. Journal of Behavioral Decision Making, 20, 103-124.

Wiesenthal, D. L. \& Singhal, D. (2005). Is it safe to use a cellular telephone while driving? In D. A. Hennessy \& D. L. Wiesenthal (Eds.), Contemporary issues in road user behavior and traffic safety (pp. 227-243). New York: Nova Science Publishers

Wiesenthal, D. L. \& Singhal, D. (2006). Evolutionary psychology, demography and driver safety research: A theoretical synthesis. Invited presentation at the Symposium on the Social Psychology of Aggression and Drunk Driving, 26 ${ }^{\text {th }}$ International Congress of Applied Psychology, Athens, Greece.

Wilson, M., \& Daly, M. (1985). Competitiveness, risk taking, and violence: The young male syndrome. Ethology and Sociobiology, 6, 59-73.

Xie, C., \& Parker, D. (2002). A social psychological approach to driving violations in two Chinese cities. Transportation Research Part F, 5, 293-308. 


\section{Table 1}

Reliability coefficients

Variable

Driving errors

Driving lapses

Driving violations

8

.808

114

Missing TASS output failure

$$
\text { Alexithymia }
$$

TASS override failure
DAPI - MFA
8
.876
115
DAPI - EFA
12
.799
114
DAPI - DAPC
5
.754
113
DAPI - DACC
4
.859
115
Inattention Scale
9
.759
110
Impulsivity Scale
19
.811
115
CFC Scale
12
.875
114
Reactivity
24
.712
115

Note: DAPI-MFA = Differential Attention Processes Inventory - Moderately Focused Attention; DAPI-EFA = Differential Attention Processes Inventory - Extremely Focused Attention; DAPIDAPC $=$ Differential Attention Processes Inventory - Dual Attention Cognitive and Physical Tasks; DAPI-DACC $=$ Differential Attention Processes Inventory - Dual Attention Two Cognitive Tasks; $\mathrm{CFC}=$ Consideration of Future Consequences. 


\section{Table 2}

Means and standard deviations for males and females on heuristic, analytic, and driver behaviour questions

\begin{tabular}{|c|c|c|c|c|c|c|c|c|}
\hline & \multicolumn{8}{|c|}{ Gender } \\
\hline & \multicolumn{3}{|l|}{ Male } & \multicolumn{3}{|c|}{ Female } & \multirow[b]{2}{*}{$t$} & \multirow[b]{2}{*}{$p$} \\
\hline & Mean & S.D. & $n$ & Mean & S.D. & $n$ & & \\
\hline $\begin{array}{l}\text { Mean driving hours } \\
\text { per day (log } \\
\text { transformed) }\end{array}$ & .41 & .20 & 54 & .34 & .18 & 48 & 1.66 & .101 \\
\hline \multicolumn{9}{|c|}{ Driver Behaviour Questionnaire } \\
\hline Driving errors & .87 & .60 & 57 & .95 & .71 & 57 & -.60 & .553 \\
\hline Driving lapses & 1.14 & .54 & 57 & 1.26 & .65 & 57 & -1.07 & .286 \\
\hline Driving violations & 2.43 & .87 & 57 & 1.82 & .85 & 57 & 3.78 & .000 \\
\hline
\end{tabular}

Missing TASS output failure
Alexithymia
2.82
.61
$58 \quad 2.71$
.71
57
.89
.373

TASS override failure

\begin{tabular}{|c|c|c|c|c|c|c|c|c|}
\hline DAPI - MFA & 3.96 & .97 & 58 & 3.68 & 1.15 & 57 & 1.41 & .161 \\
\hline DAPI - EFA & 3.32 & .62 & 58 & 3.60 & .92 & 57 & -1.91 & .059 \\
\hline DAPI - DAPC & 5.06 & .87 & 57 & 5.29 & 1.04 & 56 & -1.27 & .205 \\
\hline DAPI - DACC & 2.88 & 1.02 & 58 & 2.54 & 1.01 & 57 & 1.75 & .082 \\
\hline Inattention Scale & 2.86 & .57 & 58 & 2.88 & .50 & 57 & -.23 & .816 \\
\hline Impulsivity & 2.49 & .49 & 58 & 2.33 & .53 & 57 & 1.60 & .112 \\
\hline CFC Scale & 3.96 & .84 & 57 & 4.26 & .73 & 57 & -2.04 & .044 \\
\hline Reactivity Scale & 2.88 & .37 & 58 & 3.25 & .34 & 57 & -5.49 & .000 \\
\hline
\end{tabular}


Cognitive Tasks; $\mathrm{CFC}=$ Consideration of Future Consequences. Bold text indicates significant values. 


\section{Table 3}

Bivariate correlations between heuristic and analytic variables

$\begin{array}{llllllll}1 . & 2 . & 3 . & 4 . & 5 . & 6 . & 7 . & 8 .\end{array}$

Missing TASS output failure

1.Alexithymia

TASS override failure

2.DAPI-MFA $\quad \mathbf{- . 1 8 6}$

3.DAPI-EFA $\quad .210 \quad .067$

$.024 \quad .477$

4.DAPI-DAPC $\quad \mathbf{- . 2 0 0} \quad \mathbf{. 3 6 5} \quad .096$

$.033 \quad .000 \quad .310$

$\begin{array}{lllll}\text { 5.DAPI-DACC } & -.144 & \mathbf{. 5 5 7} & .137 & \mathbf{. 3 0 7} \\ & 126 & .000 & .144 & .001\end{array}$

$\begin{array}{llllll}6 . I n a t t e n t i o n & \mathbf{3 5 5} & -.135 & \mathbf{. 5 0 9} & -.075 & \mathbf{- . 2 0 1}\end{array}$

$\begin{array}{lllll}.000 & .152 & .000 \quad .432 & .031\end{array}$

$\begin{array}{llllllll}\text { 7.Impulsivity } & \mathbf{. 3 1 0} & .092 & \mathbf{. 3 1 5} & -.007 & .063 & \mathbf{. 4 4 5}\end{array}$

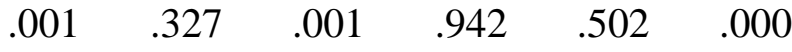

$\begin{array}{lccccccc}\text { 8.CFC Scale } & \mathbf{- . 2 4 7} & -.060 & -.096 & .019 & .037 & \mathbf{- . 2 1 7} & \mathbf{- . 4 4 1} \\ & .008 & .529 & .309 & .840 & .692 & .020 & .000\end{array}$

$\begin{array}{lllllllll}\text { 9. Reactivity } & .063 & \mathbf{- . 3 6 1} & .140 & -.154 & \mathbf{- . 2 7 4} & \mathbf{. 1 8 7} & -.058 & -.007\end{array}$

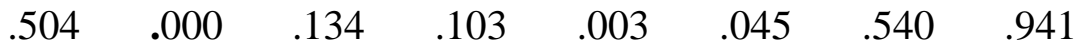

Notes: Each $p$-value is listed below its respective correlation.

DAPI-MFA = Differential Attention Processes Inventory - Moderately Focused Attention;

DAPI-EFA = Differential Attention Processes Inventory - Extremely Focused Attention; DAPI-

DAPC $=$ Differential Attention Processes Inventory - Dual Attention Cognitive and Physical

Tasks; DAPI-DACC $=$ Differential Attention Processes Inventory - Dual Attention Two

Cognitive Tasks; $\mathrm{CFC}=$ Consideration of Future Consequences. Bold text indicates statistically significant values. 
Table 4

Correlations between measures of cognitive failure and driver behaviour

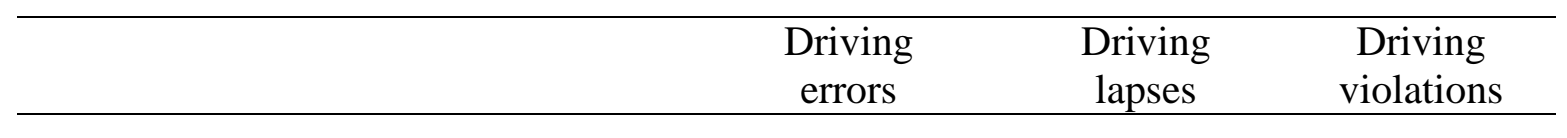

Missing TASS output failure
Alexithymia
.103
.138
.102
.273
.144
.282

TASS override failure

\begin{tabular}{|c|c|c|c|}
\hline DAPI - MFA & $\begin{array}{c}-.103 \\
.275\end{array}$ & $\begin{array}{l}.066 \\
.485\end{array}$ & $\begin{array}{l}.071 \\
.453\end{array}$ \\
\hline DAPI - EFA & $\begin{array}{l}.359 \\
.000\end{array}$ & $\begin{array}{l}.383 \\
.000\end{array}$ & $\begin{array}{l}.250 \\
.007\end{array}$ \\
\hline DAPI - DAPC & $\begin{array}{c}-.098 \\
.304\end{array}$ & $\begin{array}{c}-.085 \\
.370\end{array}$ & $\begin{array}{l}.143 \\
.133\end{array}$ \\
\hline DAPI - DACC & $\begin{array}{r}-.047 \\
.617\end{array}$ & $\begin{array}{c}-.015 \\
.875\end{array}$ & $\begin{array}{l}.195 \\
.038\end{array}$ \\
\hline Inattention Scale & $\begin{array}{l}.309 \\
.001\end{array}$ & $\begin{array}{l}.362 \\
.000\end{array}$ & $\begin{array}{l}.144 \\
.128\end{array}$ \\
\hline Impulsivity Scale & $\begin{array}{l}.272 \\
.003\end{array}$ & $\begin{array}{l}.336 \\
.000\end{array}$ & $\begin{array}{l}.470 \\
.000\end{array}$ \\
\hline CFC Scale & $\begin{array}{c}-.029 \\
.761\end{array}$ & $\begin{array}{c}-.014 \\
.881\end{array}$ & $\begin{array}{r}-.299 \\
.001\end{array}$ \\
\hline Reactivity & $\begin{array}{l}.105 \\
.267\end{array}$ & $\begin{array}{l}.165 \\
.079\end{array}$ & $\begin{array}{l}-.286 \\
.002\end{array}$ \\
\hline
\end{tabular}

Notes: Each $p$-value is listed below its respective correlation.

DAPI-MFA = Differential Attention Processes Inventory - Moderately Focused Attention;

DAPI-EFA $=$ Differential Attention Processes Inventory - Extremely Focused Attention; DAPIDAPC $=$ Differential Attention Processes Inventory - Dual Attention Cognitive and Physical Tasks; DAPI-DACC $=$ Differential Attention Processes Inventory - Dual Attention Two Cognitive Tasks; $\mathrm{CFC}=$ Consideration of Future Consequences. Bold text indicates statistically significant values. 
Table 5

Demographic and cognitive failure variables as predictors of driving behaviour

$$
\text { Unstandardized Standardized }
$$

\begin{tabular}{|c|c|c|c|c|c|c|c|}
\hline Variable & $B$ & S.E. & $\beta$ & $t$ & $p$ & $\begin{array}{c}\text { Unique } \\
\text { variance } \\
\text { explained }\end{array}$ & $\begin{array}{c}\text { Partial } \\
r\end{array}$ \\
\hline
\end{tabular}

\begin{tabular}{|c|c|c|c|c|c|c|c|}
\hline \multicolumn{8}{|l|}{ Predictors of driving errors } \\
\hline $\begin{array}{l}\text { Gender }(1=\text { male, } \\
2=\text { female })\end{array}$ & .102 & .133 & .078 & .77 & .443 & .006 & .078 \\
\hline $\begin{array}{l}\text { Mean driving hours } \\
\text { per day }\end{array}$ & .455 & .343 & .134 & 1.32 & .189 & .017 & .133 \\
\hline \multicolumn{8}{|l|}{ Step 2} \\
\hline $\begin{array}{l}\text { Gender }(1=\text { male }, \\
2=\text { female })\end{array}$ & .066 & .128 & .050 & .51 & .609 & .002 & .053 \\
\hline $\begin{array}{l}\text { Mean driving hours } \\
\text { per day }\end{array}$ & .434 & .331 & .128 & 1.31 & .193 & .015 & .133 \\
\hline DAPI - EFA & .192 & .093 & .232 & 2.07 & .041 & .037 & .208 \\
\hline ASRS - Inattention & .190 & .145 & .155 & 1.31 & .194 & .015 & .133 \\
\hline Eysenck's Impulsivity & .150 & .138 & .118 & 1.09 & .280 & .010 & .111 \\
\hline
\end{tabular}

$R^{2}=.021$ for Step $1, p=.360$

$\Delta R^{2}=.161$ for Step 2, $p=.001$

Final regression $F=4.220, p=.002$, Adjusted $R^{2}=.139$

$N=101$

Predictors of driving lapses

Step 1

\begin{tabular}{|c|c|c|c|c|c|c|c|}
\hline $\begin{array}{l}\text { Gender }(1=\text { male } \\
2=\text { female })\end{array}$ & .142 & .120 & .120 & 1.18 & .239 & .014 & .119 \\
\hline $\begin{array}{l}\text { Mean driving hours } \\
\text { per day }\end{array}$ & .361 & .311 & .117 & 1.16 & .249 & .013 & .116 \\
\hline \multicolumn{8}{|l|}{ Step 2} \\
\hline $\begin{array}{l}\text { Gender }(1=\text { male }, \\
2=\text { female })\end{array}$ & .125 & .113 & .105 & 1.11 & .271 & .010 & .113 \\
\hline $\begin{array}{l}\text { Mean driving hours } \\
\text { per day }\end{array}$ & .330 & .292 & .107 & 1.13 & .261 & .010 & .115 \\
\hline DAPI - EFA & .158 & .082 & .210 & 1.93 & .056 & .030 & .195 \\
\hline ASRS - Inattention & .205 & .128 & .184 & 1.61 & .112 & .021 & .163 \\
\hline Impulsivity Scale & .216 & .122 & .187 & 1.78 & .079 & .026 & .179 \\
\hline
\end{tabular}

$R^{2}=.024$ for Step $1, p=.312$

$\Delta R^{2}=.208$ for Step 2, $p=.000$

Final regression $F=5.709, p=.000$, Adjusted $R^{2}=.191$ 
$N=101$

Predictors of driving violations

Step 1

Gender $\left(1=\right.$ male, $\quad \quad \begin{array}{llllllll} & -.541 & .170 & -.299 & \mathbf{- 3 . 1 9} & .002 & .087 & -.307\end{array}$ $2=$ female)

$\begin{array}{llllllllll}\text { Mean driving hours } & 1.082 & .439 & & .231 & & \mathbf{2 . 4 6} & .015 & .052 & .242\end{array}$ per day

Step 2

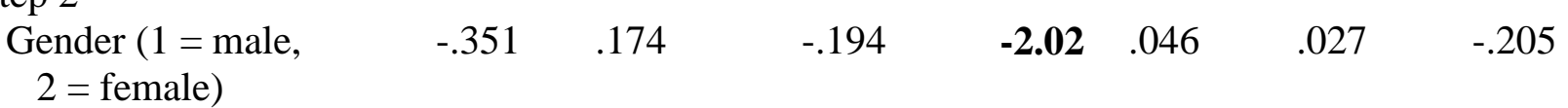

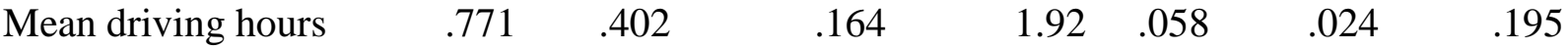
per day

Reactivity

DAPI - EFA

$-.412 \quad .215$

$-.181$

$\begin{array}{lll}-1.91 & .059 \quad .024\end{array}$

$-.195$

$.230 \quad .103$

.200

$2.23 \quad .028$

.033

.225

DAPI - DACC

$.024 \quad .079$

.027

$.300 \quad .765$

.001

.031

Impulsivity Scale

$.520 \quad .171$

.295

$3.05 \quad .003$

.061

.301

CFC

$-.120 \quad .105$

$-.106$

$\begin{array}{lll}-1.15 & .255 & .009\end{array}$

$-.118$

$R^{2}=.165$ for Step $1, p=.000$

$\Delta R^{2}=.223$ for Step 2, $p=.000$

Final regression $F=8.437, p=.000$, Adjusted $R^{2}=.342$

$N=101$

Note: DAPI-EFA = Differential Attention Processes Inventory - Extremely Focused Attention; DAPI-DACC $=$ Differential Attention Processes Inventory - Dual Attention Two Cognitive Tasks; $\mathrm{CFC}=$ Consideration of Future Consequences. Bold text indicates statistically significant values. 